\title{
TECNOLOGIAS ASSISTIVAS E ACESSIBILIDADE PARA IDOSOS: ANÁLISE EM SUPERMERCADOS
}

\section{ELDERLY'S ASSISTIVE TECHNOLOGY AND ACESSIBILITY: SUPERMARKETS ANALYSIS}

\author{
Jéssica Celeski ${ }^{1}$, tecg. \\ Elton Moura Nickel ${ }^{2}$, D.Sc \\ Alexandre Amorim dos Reis ${ }^{3}$, D.Sc \\ (1) Universidade Estadual de Santa Catarina \\ e-mail: jessicaceleski@gmail.com \\ (2) Universidade Estadual de Santa Catarina \\ e-mail: eltonnickel@gmail.com \\ (3) Universidade Estadual de Santa Catarina \\ e-mail:alexandre.a.reis@gmail.com
}

Tecnologias assistivas, idosos, supermercado.

Este artigo visa revisar a bibliografia existente acerca de tecnologias assistivas e acessibilidade para ambientes de supermercado, relacionadas ao público idoso. Além disso, são verificados, a partir de um estudo de caso, diversos aspectos que podem influenciar na experiência do consumidor idoso neste ambiente.

Assistive technologies, elderly, supermarkets.

This article aims to review existing bibliography about assistive technologies and accessibility to supermarket environments related to the elderly public. In addition, a number of aspects that may influence the experience of the elderly consumer in this environment been verified from a case study.

\section{Introdução}

Nesse artigo, pretende-se integrar as áreas do design, ergonomia e projeto de interiores, na investigação das interações entre o consumidor idoso e o espaço físico do supermercado. A proposta da pesquisa foi analisar os ambientes dos supermercados, sob o ponto de vista da ergonomia e da usabilidade, com o objetivo de elencar alguns problemas vivenciados pelo público idoso.

Com esta pesquisa, pretende-se revisar a bibliografia existente sobre idosos, regulamentação para acessibilidade e tecnologias assistivas, assim como compreender as necessidades específicas do 


\section{$16^{\circ}$ \\ ERGODESIGN USIHC CINAHPA}

público idoso no ambiente do supermercado.

A metodologia utilizada consiste em analisar os supermercados da região da Grande Florianópolis e verificar o ambiente. Foram considerados aspectos que referem-se ao acesso, a circulação nos corredores, a sinalização dos setores e de emergência, o alcance dos produtos nas prateleiras, a iluminação, o revestimento do piso e a existência de caixa preferencial e banheiro acessível, assim como a existência de tecnologias assistivas.

A partir disso é possível identificar a necessidade de soluções para adaptações nas configurações projetuais e através dessa análise, definir parâmetros de projeto que promovem o bem-estar dos idosos, para que usufruam dos ambientes dos supermercados com segurança e sem esforços desnecessários.

\section{Revisão bibliográfica}

\subsection{Idosos}

O idoso ou terceira idade é todo indivíduo que possui acima de 60 anos. Segundo o Estatuto do Idoso (2016), o envelhecimento da população é um fenômeno mundial que, nos anos mais recentes, ganha maior importância nos países em desenvolvimento.

No Brasil, o crescimento da população idosa é cada vez mais relevante, tanto em termos absolutos quanto proporcionais. Os efeitos do aumento desta população já são percebidos nas demandas sociais, nas áreas de saúde e na previdência.

Dados do Instituto Brasileiro de Geografia e Estatística (IBGE,2016) apontam que os brasileiros com mais de 60 anos de idade, no ano de 2016 representam $12,11 \%$ da população. Sendo que dentre esses, $6,75 \%$ são mulheres e 5,35\% são homens. Estima-se que até o ano 2030, esse público representará $18,62 \%$ da população. Sendo $10,31 \%$ mulheres e $8,31 \%$ homens.

Os idosos são usuários complexos, pois cada modificação fisiológica pode acarretar uma limitação diferente, no uso do espaço e de $16^{\circ}$ Ergodesign - Congresso Internacional de Ergonomia e Usabilidade de Interfaces Humano Tecnológica: Produto, Informações Ambientes Construídos e Transporte

$16^{\circ}$ USIHC - Congresso Internacional de Ergonomia e Usabilidade de Interfaces Humano Computador

CINAHPA | 2017 - Congresso Internacional de Ambientes Hipermídia para Aprendizagem. equipamentos. Cada indivíduo é único e possui necessidades específicas, portanto o símbolo da pessoa idosa (figura 1) não atende igualmente a todos. Por exemplo, um idoso com problemas visuais tem dificuldade em se orientar e se localizar, assim como pode ter tempo de reação mais lento. (ELY; DORNELES,2006)

Para entender o processo de envelhecimento é preciso analisar três aspectos principais onde estas modificações ocorrem. Sendo os aspectos: socioeconômico, psicocognitivo e biológico/ funcional. É importante salientar, ainda, que as diversas alterações, ocorridas no organismo dos idosos, podem variar de pessoa para pessoa, conforme suas condições físicas, o meio ambiente o qual está inserida e seu estilo de vida (SIMÕES, 1994 apud ELY; DORNELES, 2006).

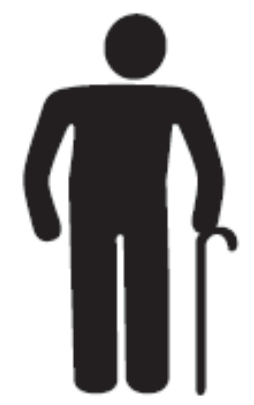

Figura 1 - Símbolo da pessoa idosa Fonte: ABNT (2015)

\subsection{0 consumidor idoso}

Longe de ser frágil, muitas pessoas idosas mantémse independentes, em boas condições físicas, realizam as tarefas do cotidiano e contribuem com suas famílias. Devem ser considerados os usuários idosos não somente porque são um público que cresce cada vez mais, mas também porque as necessidades específicas e funcionais deste público são consideravelmente diferentes quando relacionados aos jovens, nas seguintes áreas: cognição, percepção, controle motor e motivação.

As capacidades e limitações da crescente população idosa deve ser compreendida e levada em consideração para o processo de design e a pesquisa em fatores humanos para garantir que esse segmento da população possa interagir com
Realização:

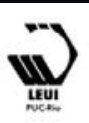




\section{$16^{\circ}$ \\ ERGODESIGN USIHC CINAHPA}

produtos e serviços de uma maneira segura, eficiente e eficaz (SALVENDY, 2006).

\subsection{Experiência do usuário}

Conforme estudos sobre a experiência do usuário, são abordados sete aspectos que envolvem etapas de antes, durante e após o uso de serviços, descritas por diversos autores (tabela 1).

\begin{tabular}{|c|c|}
\hline $\begin{array}{l}\text { ASPECTOS DA } \\
\text { EXPERIÊNCIA }\end{array}$ & $\begin{array}{l}\text { ASPECTOS OBSERVADOS E } \\
\text { MENSURADOS }\end{array}$ \\
\hline $\begin{array}{c}\text { FÍSICO } \\
\text { (AMBIENTE) }\end{array}$ & $\begin{array}{l}\text { Ambiente, acessibilidade, usabilidade } \\
\text { (NIELSEN, 2007). }\end{array}$ \\
\hline ESTÉTICO & $\begin{array}{l}\text { Atributos estéticos - cores, formas, } \\
\text { texturas (COATES, 2003). }\end{array}$ \\
\hline SENSORIAL & $\begin{array}{l}\text { Sentidos - olfato, paladar, visão, tato e } \\
\text { audição (MUNARI, 2008). }\end{array}$ \\
\hline EMOCIONAL & $\begin{array}{l}\text { Emoções percebidas, influência do humor } \\
\text { (NORBERT, 2000). }\end{array}$ \\
\hline MOTIVACIONAL & $\begin{array}{l}\text { Expectativas, previsão de interação } \\
\text { (HASDOGAN, 1996). }\end{array}$ \\
\hline SOCIAL & $\begin{array}{l}\text { Nível de socialização (DOUGLAS e } \\
\text { ISHERWOOD, 2006). }\end{array}$ \\
\hline ENVOLVIMENTO & $\begin{array}{l}\text { Interação, fidelização, experiências } \\
\text { pessoais (conexão) e atributos do produto } \\
\text { (DAMAZIO e MONTALVÃO, 2008). }\end{array}$ \\
\hline
\end{tabular}

Tabela 1- Aspectos da experiência Fonte: Adaptado de DEMILIS; REIS (2016)

Nesta pesquisa, propõe-se investigar quais fatores influenciam a interação e experiência de consumo dos idosos no ambiente físico do supermercado.

\subsection{Tecnologias Assistivas}

A Tecnologia assistiva deve ser entendida como um auxílio, sendo este um produto ou serviço, que promoverá a ampliação de uma habilidade funcional deficitária ou possibilitará a realização $16^{\circ}$ Ergodesign - Congresso Internacional de Ergonomia e Usabilidade de Interfaces Humano Tecnológica: Produto, Informações Ambientes Construídos e Transporte

$16^{\circ}$ USIHC - Congresso Internacional de Ergonomia e Usabilidade de Interfaces Humano Computador

CINAHPA | 2017 - Congresso Internacional de Ambientes Hipermídia para Aprendizagem.

da função desejada. No qual, função que se encontra impedida por circunstância de deficiência ou pelo envelhecimento. (BERSCH, 2013).

Projetos de edificação e urbanismo que garantem acesso, funcionalidade e mobilidade a todas as pessoas, independente de sua condição física e sensorial. Adaptações estruturais e reformas na casa e/ou ambiente de trabalho, através de rampas, elevadores, adaptações em banheiros, mobiliário entre outras, que retiram ou reduzem as barreiras físicas. (BERSCH, 2013)

Podemos então dizer que o objetivo maior da tecnologia assistiva é proporcionar à pessoa maior independência, qualidade de vida e inclusão social, através da ampliação de sua comunicação, mobilidade, controle de seu ambiente, habilidades de seu aprendizado e trabalho. (BERSCH, 2013)

\subsection{Acessibilidade}

A NBR 9050 trata da acessibilidade espacial e visa proporcionar a utilização de maneira autônoma, independente e segura dos espaços indiferente de condições como: idade, estatura, limitação de mobilidade ou percepção do indivíduo.

No estabelecimento desses critérios e parâmetros técnicos foram consideradas diversas condições de mobilidade e de percepção do ambiente, com ou sem a ajuda de aparelhos específicos, como próteses, aparelhos de apoio, cadeiras de rodas, bengalas de rastreamento, sistemas assistivos de audição ou qualquer outro que venha a complementar necessidades individuais. (ABNT, 2015)

O termo acessibilidade é definido pela NBR 9050 como a possibilidade e condição de alcance, percepção e entendimento para utilização, com segurança e autonomia, de espaços, mobiliários, equipamentos urbanos, edificações, transportes, 


\section{$16^{\circ}$ \\ ERGODESIGN USIHC CINAHPA}

informação e comunicação, inclusive seus sistemas e tecnologias, bem como outros serviços e instalações abertos ao público, de uso público ou privado de uso coletivo, tanto na zona urbana como na rural, por pessoa com deficiência ou mobilidade reduzida. Também define o desenho universal como sendo: "[...] aquele que visa atender a maior gama de variações possíveis das características antropométricas e sensoriais da população". (ABNT, 2015)

A Comissão Permanente de Acessibilidade da Secretaria Especial da Pessoa com Deficiência e Mobilidade Reduzida da Cidade de São Paulo (2005) cita que os principais obstáculos encontrados em edificações acontecem em áreas de acessos, circulação horizontal e vertical, aberturas (portas e janelas), sanitários, vestiários, piscinas e mobiliários (telefones, balcões, bebedouros, etc.)" (ROSSI et al, 2010).

A rota acessível é um trajeto contínuo, desobstruído e sinalizado, que conecta os ambientes externos e internos de espaços e edificações, e que pode ser utilizada de forma autônoma e segura por todas as pessoas. A rota acessível externa incorpora estacionamentos, calçadas, faixas de travessias de pedestres (elevadas ou não), rampas, escadas, passarelas e outros elementos da circulação. A rota acessível interna incorpora corredores, pisos, rampas, escadas, elevadores e outros elementos da circulação.

Conforme a legislação brasileira, todo ambiente comercial deve conter no mínimo um sanitário acessível. Devem ser consideradas as dimensões mínimas necessárias para transferência e manobra do cadeirante para que possa utilizar o sanitário adequadamente e acessar a pia.

Para que os espaços sejam acessíveis, deve-se considerar os quatro componentes da acessibilidade: orientação/informação, deslocamento, uso e comunicação, identificados por Dischinger e Bins Ely (2006).

Orientação e informação: os ambientes devem ser espacialmente compreensíveis e apresentar $16^{\circ}$ Ergodesign - Congresso Internacional de Ergonomia e Usabilidade de Interfaces Humano Tecnológica: Produto, Informações Ambientes Construídos e Transporte

$16^{\circ}$ USIHC - Congresso Internacional de Ergonomia e Usabilidade de Interfaces Humano Computador

CINAHPA | 2017 - Congresso Internacional de Ambientes Hipermídia para Aprendizagem. diferentes formatos de informações, como placas, mapas, sinalização sonora, etc. O uso de cores diferentes e com contraste devem ser utilizadas em áreas para idosos, pois facilitam a percepção dos espaços e podem evitar acidentes.

Deslocamento: o cuidado com os tipos de pisos a serem implantados é importante, pois devem ser antiderrapantes e antirreflexo, para evitar quedas e ofuscamento, respectivamente. (ELY,

DORNELES, 2006)

Comunicação: corresponde à facilidade de interação entre os usuários com o ambiente, pode ser garantida a partir de configurações espaciais ou de tecnologias assistivas. Em espaços muito amplos e com muitas funções e possibilidades de atividades, sugere-se a implantação de quiosques de informações e terminais computadorizados, principalmente para o caso de pessoas com problemas auditivos e de produção linguística.

\subsection{Supermercado}

O supermercado é local para suprir as necessidades fisiológicas e diárias de alimentação, sendo um destino comum dos idosos, além disso, pode ser um local de socialização. Por isso, "tem grande importância não só para a manutenção de sua dispensa de alimentos, mas serve também como fonte de lazer e diversão" (FADIGATTI ET AL, 2015).

Estes tipos de estabelecimentos comerciais, como o supermercado, podem se diferenciar "pela forma que prestam os serviços, o uso de diferentes tecnologias, olhares particulares para o público que atendem, propondo, por exemplo, serviços voltados para idosos". (DEMILIS; REIS, 2015)

Alguns problemas na interação do usuário idoso com o ambiente do supermercado podem ser citados, como "prateleiras muito altas ou muito baixas, piso escorregadio, falta de sinalização, placas pouco contrastantes, quando há, placas ilegíveis e preços dispostos de forma confusa ou pouco legíveis". (FADIGATTI ET AL, 2015)

Diversas situações relacionadas à dificuldade de 


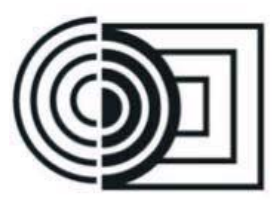
CINAHPA $16^{\circ}$ Ergodesign - Congresso Internacional de Ergonomia e Usabilidade de Interfaces Humano Tecnológica: Produto, Informações Ambientes Construídos e Transporte

$16^{\circ}$ USIHC - Congresso Internacional de Ergonomia e Usabilidade de Interfaces Humano Computador

CINAHPA | 2017 - Congresso Internacional de Ambientes Hipermídia para Aprendizagem. alcance dos produtos podem ser observadas no ambiente do supermercado, o que pode ocasionar a desistência de compra do produto em específico ou então situações constrangedoras limitando a autonomia do idoso; ou até perigosas, quando improvisam maneiras de acessar o item desejado. Exemplo disso é citado por Underhill (2009) "Vimos uma senhora idosa usar uma caixa de papel-alumínio para atingir sua marca favorita de biscoitos para cães e derrubá-la da prateleira”.

Com base numa pesquisa, buscou-se determinar o valor dado pelos usuários idosos para os aspectos físicos, estéticos, sensoriais, emocionais, motivacionais, sociais e de envolvimento na experiência de uso nos serviços de supermercados. Neste, é possível perceber que é preciso dar ênfase na funcionalidade do espaço de varejo e a forma como o ambiente de compras está organizado, melhorando a experiência do usuário idoso e interação com o espaço físico. (DEMILIS; REIS, 2015)

\section{Metodologia}

A metodologia utilizada consiste em analisar quatro supermercados da região da Grande Florianópolis e verificar os aspectos para interação apropriada no ambiente, assim como as tecnologias assistivas existentes.

Os aspectos analisados referem-se ao acesso, a circulação nos corredores, a sinalização dos setores e de emergência, o alcance dos produtos nas prateleiras, a iluminação, o revestimento do piso e a existência de caixa preferencial e banheiro acessível, assim como a existência de tecnologias assistivas, como o carrinho de compras automatizado.

Para o presente estudo estes aspectos foram analisados em quatro supermercados da região da Grande Florianópolis (tabela 2 e tabela 3).

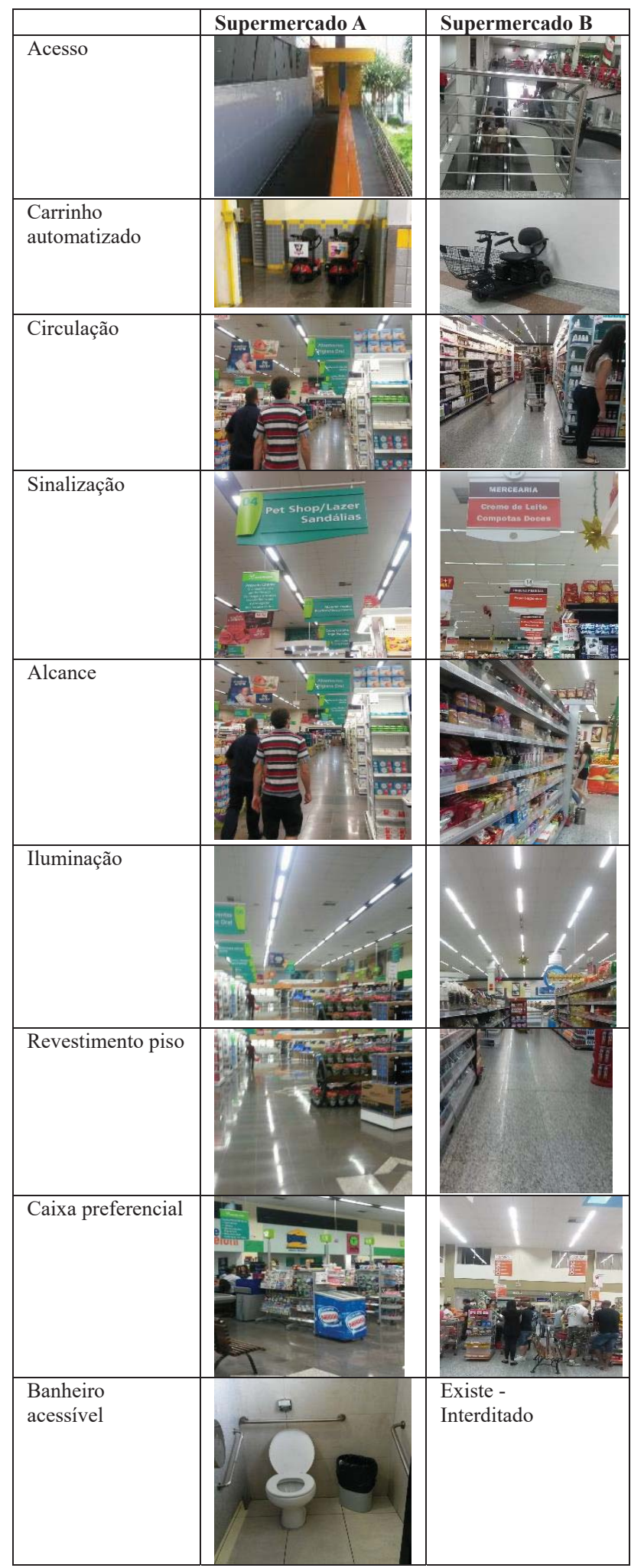

Tabela 2 - Supermercados A e B

Fonte: elaborado pelo autor 


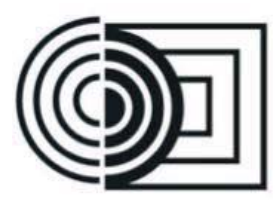
CINAHPA

$16^{\circ}$ Ergodesign - Congresso Internacional de Ergonomia e Usabilidade de Interfaces Humano Tecnológica: Produto, Informações Ambientes Construídos e Transporte

$16^{\circ}$ USIHC - Congresso Internacional de Ergonomia e Usabilidade de Interfaces Humano Computador

CINAHPA | 2017 - Congresso Internacional de Ambientes Hipermídia para Aprendizagem.

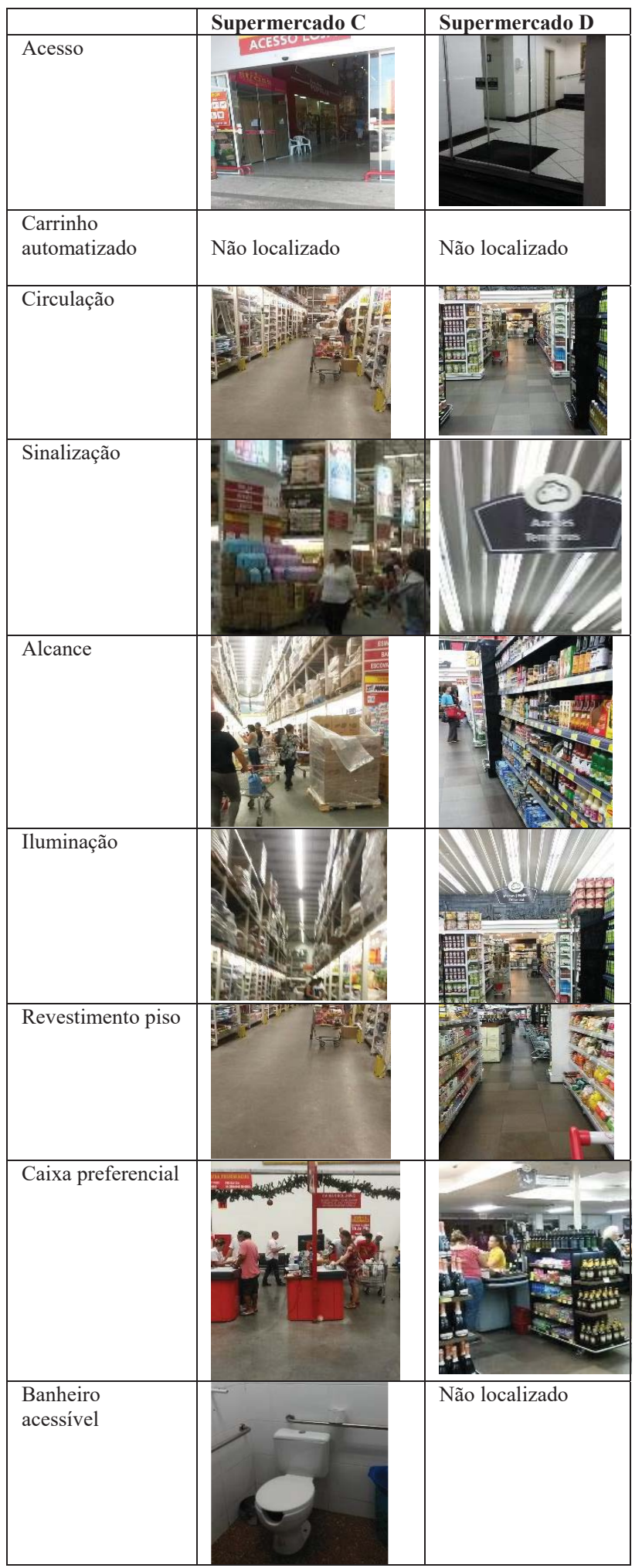

Tabela 3 - Supermercados C e D Fonte: elaborado pelo autor

\section{Estudo de caso}

A partir das visitas aos supermercados, foram observados e analisados os diferentes aspectos e descritos conforme abaixo, relacionando com a bibliografia revisada:

Acesso: quanto ao acesso, recomenda-se porta de abertura automática, rampas com corrimão em ambos lados, e vãos largos que permitam livre entrada e saída de várias pessoas simultaneamente.

No supermercado A existe uma rampa para acesso pela rua, porém o corrimão existe somente em um lado, seguido de uma porta com abertura automática. Há outra rampa pelo estacionamento, com corrimão nos dois lados, mas sem continuidade adequada.

No supermercado B, existe uma rampa e uma escada rolante, seguida de porta com abertura automática.

O supermercado $\mathrm{C}$ é localizado no térreo, possui uma leve inclinação e porta com abertura automática.

O supermercado D contém dois acessos, no acesso pela rua possui alguns degraus e a porta automática, já pelo estacionamento possui dois degraus, a porta automática e então uma escada com corrimão em ambos lados.

Tecnologia Assistiva: o carrinho para compras automatizado é considerado uma tecnologia assistiva no supermercado, pode auxiliar as pessoas com mobilidade reduzida a locomoveremse no local.

Porém, os carrinhos automatizados analisados neste estudo de caso, podem dificultar o alcance aos produtos que encontram-se em prateleiras altas e baixas, assim como limita-se ao alcance lateral, considerando que a compartimento para os itens normalmente ocupa a parte frontal do carrinho. Além disso, o compartimento para armazenar os produtos possui uma dimensão reduzida em relação aos carrinhos convencionais, limitando a quantidade e dimensão dos produtos a serem comprados.
Realização:

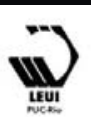




\section{$16^{\circ}$ \\ ERGODESIGN USIHC CINAHPA}

$16^{\circ}$ Ergodesign - Congresso Internacional de Ergonomia e Usabilidade de Interfaces Humano Tecnológica: Produto, Informações Ambientes Construídos e Transporte

$16^{\circ}$ USIHC - Congresso Internacional de Ergonomia e Usabilidade de Interfaces Humano Computador

CINAHPA | 2017 - Congresso Internacional de Ambientes Hipermídia para Aprendizagem.
Os carrinhos automatizados foram encontrados nos supermercados A e B, sendo que o B possui maior compartimento para compras. Nos supermercados C e D não foi localizada a existência destes.

Circulação: quanto à circulação, conforme a NBR 9050, o fluxo de pessoas deve determinar as dimensões dos corredores. Entretanto, a largura dos corredores deve ser de no mínimo $1,20 \mathrm{~m}$ se o corredor tiver até $10 \mathrm{~m}$ e de $1,50 \mathrm{~m}$ se o corredor tiver mais de $10 \mathrm{~m}$.

Quando um caminho possui móveis e objetos, que é o caso dos supermercados, a pessoa é induzida ou conduzida a seguir em determinados sentidos, dizse que a circulação é forçada. Nessa situação, é necessário caminhar com mais atenção e sintonia no percurso, pois é preciso "buscar referências e indicações sobre a direção a seguir". (GURGEL, 2005, p.28) Para o público idoso, essa atenção deve ser redobrada, pois têm propensão a dificuldades cognitivas e na percepção sensorial, podendo sentirem-se confusos e desorientados para encontrarem os itens desejados.

Todos supermercados analisados aparentam possuir dimensão adequada, recomenda-se medição no local para conferência. Nos corredores entre gôndolas e entre setores, porém próximo aos caixas essas dimensões são reduzidas. Destaca-se o supermercado $\mathrm{C}$, que possui os corredores mais largos, provavelmente porque o estabelecimento é varejista e atacadista, além de possuir os maiores carrinhos de compras.

Sinalização: em relação à sinalização para ambientes comerciais, existem alguns tipos de sinalização: a permanente, que identifica os espaços e elementos; a direcional, que indica a direção de um percurso ou distribuição espacial; a sinalização de emergência, a qual indica rotas de fuga e saídas de emergência e a temporária, que traz informações provisórias ou que podem ser alteradas conforme o tempo. (GURGEL, 2005)

Nos supermercados analisados, a sinalização identifica os setores, agrupando os produtos por categorias, além disso, os sanitários são identificados, assim como os caixas preferenciais.
Também existe a sinalização de emergência, identificando as saídas. Nas placas, todas possuem contraste de cores e dimensão de fonte aparentemente legível. Recomenda-se análises mais técnicas para certificar esses dados relacionados à legibilidade.

Nos supermercados A, B e D as placas encontramse no corredor, suspensas com cabo a partir do forro e no supermercado C, a sinalização encontrase nas gôndolas.

Alcance: para permitir o alcance dos produtos, tanto físico, quanto visual, devem ser considerados aspectos antropométricos do usuário, assim como as limitações de movimentação específicas dos consumidores idosos.

Em todos supermercados percebe-se que os produtos estão expostos em prateleiras altas e baixas, para avaliar o alcance para este público específico, recomenda-se testes ergonômicos mais aprofundados, assim como análise da tarefa. $\mathrm{O}$ espaçamento entre prateleiras aparenta ser adequado para manuseio, sendo muito variável, dependendo de cada produto exposto.

Iluminação: na maioria dos supermercados, a iluminação é completamente artificial, assim influencia na percepção de tempo do usuário. "É bem conhecida a tática de alguns shoppings centers de criar uma atmosfera totalmente desconectada com o exterior a fim de evitar que os usuários percebam se está escurecendo ou chovendo e se concentrem somente no consumo" (GURGEL, 2005, p.39).

Lojas de departamento, supermercados ou ainda lojas que comercializam produtos em grandes quantidades ficam mais bem iluminados com luz clara e bastante eficaz. Nesse caso, a estética da iluminação não precisa ser muito considerada pois os clientes sabem o que encontrar nessas lojas e comportam-se de maneira mais objetiva e racional". (GURGEL, 2005, p.56) 


\section{$16^{\circ}$ \\ ERGODESIGN USIHC CINAHPA}

A iluminação apropriada é um fator crítico para otimizar a percepção da informação pelo público idoso. A iluminação deve ser nivelada para reduzir o brilho intenso, as fontes de luz devem ser difusas, múltiplas e posicionadas para que não fiquem expostas diretamente para a pessoa, de maneira a criar uma iluminação ambiente agradável e evitar sombreamentos. Espelhos e superfícies brilhantes devem ser evitadas, pois a adaptação para ambientes claros e escuros é mais demorada no público idoso, devido a alterações na entrada de luz pela retina causadas pelo avanço da idade. (SALVENDY, 2006)

Devem ser considerados os materiais e cores dos elementos, pois a luz é refletida nestes. A luz pode ser classificada segundo sua função, a iluminação conhecida como geral, é aquela que torna possível ver o espaço como um todo, permitindo caminhar e circular pelos ambientes sem dificuldade.

Em todos supermercados analisados nesse estudo de caso, a iluminação é geral, difusa e múltipla, assim como as lâmpadas utilizadas são brancas e frias. Em todos casos, é utilizada a tática de isolar a visualização do ambiente externo, evitando que os usuários percebam o tempo percorrido no local.

Revestimentos: o revestimento do piso influi na acústica, na reflexão da luz e na manutenção dos ambientes. Para ambientes comerciais, não deve ser escorregadio e nem causar distorção visual, sendo preferencialmente de tom neutro.

Em todos supermercados analisados, o revestimento do piso possui cor neutra, é lavável e antiderrapante. Nos supermercados A, B e D o piso é em placas e no supermercado $\mathrm{C}$, o piso é homogêneo, sem emendas. Uma observação em relação ao piso do supermercado A é a refletância acentuada, podendo ser desconfortável para pessoas que possuem sensibilidade a iluminação excessiva.

Serviço: o caixa preferencial é principal serviço diferenciado destinado para idosos, gestantes e portadores de necessidades especiais, visando agilizar o processo de finalização da compra e pagamento. $16^{\circ}$ Ergodesign - Congresso Internacional de Ergonomia e Usabilidade de Interfaces Humano Tecnológica: Produto, Informações Ambientes Construídos e Transporte

$16^{\circ}$ USIHC - Congresso Internacional de Ergonomia e Usabilidade de Interfaces Humano Computador

CINAHPA | 2017 - Congresso Internacional de Ambientes Hipermídia para Aprendizagem.

Todos supermercados possuem no mínimo um caixa preferencial, destacando-se o supermercado $\mathrm{B}$, que possui três caixas para este público.

Sanitário: Em relação ao sanitário acessível, no supermercado A, encontra-se junto aos outros sanitários, separado por gênero, aos fundos, uma cabine para o vaso sanitário, com medidas aparentemente adequadas para movimentação, já a pia está localizada fora da cabine, rebaixada com vão para as pernas junto de uma bancada em mármore com cubas embutidas.

No supermercado B, encontra-se da mesma maneira que o $\mathrm{A}$, porém a cabine do sanitário acessível estava interditada, assim não foi possível verificar se estava adequado e fotografar.

No supermercado $\mathrm{C}$, o sanitário é unissex e individual, possui dimensões adequadas, porém, recomenda-se um dispositivo para acendimento automático das luzes, pois está inacessível para cadeirantes.

No supermercado D, não foi localizado o sanitário acessível, apenas convencional, próximo a escada.

\section{Considerações}

Neste estudo, o objetivo foi verificar a bibliografia existente relacionada a tecnologias assistivas para supermercados, porém poucos estudos foram encontrados acerca desse assunto em específico. Sobre acessibilidade em ambientes comerciais, o assunto já é discutido amplamente, entretanto foram poucas análises relacionadas ao ambiente do supermercado, abrangendo os diversos aspectos relacionados. Por isso, acredita-se que este artigo possa contribuir e guiar futuros pesquisadores a compreender a relação entre os aspectos referidos.

A partir das análises realizadas nos supermercados foi possível obter informações que possibilitam propostas de adequações e parâmetros para projeto de design de interiores em ambientes comerciais que contemplem as necessidades do público idoso. É papel dos projetistas e ergonomistas, portanto, conhecer estas necessidades, para proporem ambientes e objetos acessíveis, seguros e 


\section{$16^{\circ}$}

ERGODESIGN USIHC CINAHPA

$16^{\circ}$ Ergodesign - Congresso Internacional de Ergonomia e Usabilidade de Interfaces Humano Tecnológica: Produto, Informações Ambientes Construídos e Transporte

$16^{\circ}$ USIHC - Congresso Internacional de Ergonomia e Usabilidade de Interfaces Humano Computador

CINAHPA | 2017 - Congresso Internacional de Ambientes Hipermídia para Aprendizagem.

confortáveis para os mais diversos públicos.

Para pesquisas futuras, sugere-se aprofundamento sobre cada aspecto abordado, com análise técnicas e considerando estudos como observação do usuário idoso no ambiente, análise da tarefa e entrevistas estruturadas, por exemplo.

\section{Referências Bibliográficas}

\section{ASSOCIAÇÃO BRASILEIRA DE NORMAS} TÉCNICAS. Norma NBR 9050 - Acessibilidade de pessoas com deficiência a edificações, espaço, mobiliário e equipamentos urbanos. Rio de Janeiro, 2004. 97 p.

ELY, Vera Helena Moro Bins; DORNELES, Vanessa Goulart. Acessibilidade espacial do idoso no espaço livre urbano. ABERGO: 2006.

\section{BERSCH, Rita. Introdução a Tecnologias}

Assistivas. 2013. Disponível em:

www.assistiva.com.br

COOK, A. M.; HUSSEY, S. M. Assistive

Technologies: Principles and Practices. St. Louis, Missouri. Mosby - Year Book, Inc, 1995.

DEMILIS, Marcelo Pereira, REIS, Alexandre Amorim dos. Human factors in Service Design: valuation of consumption's experience aspects in supermarkets by the elderly population. In Product: Management \& Development. Vol. 14, 2016.

IBGE. Projeção da população do Brasil e das Unidades da Federação. Disponível em: http://www.ibge.gov.br/apps/populacao/projecao. Acesso em 21/09/2016.

FADIGATTI, Thaylla F. Mazzei; RIGOLINO, Marcelo Rolan; MEDOLA, Fausto Orsi; PASCHOARELLLI, Luis Carlos. Necessidades especiais e dificuldades do idoso no ambiente de supermercado: uma revisão dos aspectos ergonômicos. p. 224-232 . In: Anais do $15^{\circ}$ Ergodesign \& Usihc [=Blucher Design Proceedings, vol. 2, num. 1]. São Paulo: Blucher, 2015.
GURGEL, Miriam. Projetando Espaços: guia de arquitetura de interiores para áreas comerciais. São Paulo: Editora SENAC, 2005.

PANERO, Julius; ZELNIK Martin.

Dimensionamento Humano para Espaços

Interiores. Barcelona: Ed. Gustavo Gilli,2002.

ROSSI, Marco Antonio; PRADO, Bruna de Brito; MARTINS, Juliana Cavalini; ROMERO, Laís Bim. Proposta integrada de acessibilidade e design de interior: estudo de caso em ambiente de supermercado. PARC Pesquisa em Arquitetura e Construção. vol. 1, N5. Unicamp. 2010

SALVENDY, Gavriel. Handbook of Human Factors and Ergonomics. Hoboken, NJ: John Wiley \& Sons, 2006.

NETO, João Carlos Martins; ROLLEMBERG, Rodrigo Sobral. Tecnologias Assistivas e a Promoção da Inclusão Social. Ministério da Ciência e Tecnologia - MCT. Brasília: 2005. 